\title{
Determination of Population Structure of Yellow Dwarf Coconut Population in Sri Lanka
}

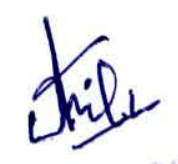

By

Liyanage Chandima Jayamali Kamaral

Thesis submitted to the University of Sri Jayewardenepura for the award of the Degree of Master of Philosophy in Botany on $25^{\text {th }}$ of September, 2014 
I certify that the candidate has incorporated all corrections, amendments and additions recommended by the examiners.

\section{Aconferey s/5/2015}

Dr. S.A.C.N.Perera

Principle Geneticist and Plant Breeder,

Genetics and Plant Breeding Division,

Coconut Research Institute,

Lunuwila, Sri Lanka.

\section{dipleti..."105/2015}

Dr. P. N. Dassanayaka

Senior Lecture,

Department of Botany,

University of Sri Jayawardanapura. 
"The work described in this thesis was carried out by me under the supervision of Dr. S.A.C.N. Perera and Dr. P.N. Dassanayaka and a report on this has not been submitted in whole or in part to any university or any other institution for another Degree/Diploma."

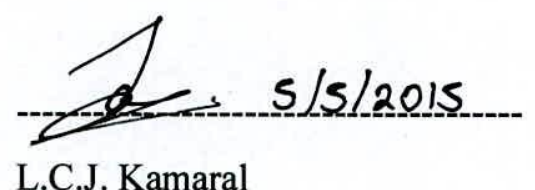

L.C.J. Kamaral 
"We certify that the above statement made by the candidate is true and that this thesis suitable for submission to the University for the purpose of evaluation"

Clistie -11/05/2015

Dr. (Mrs) P. N. Dassanayaka

(Internal supervisor)

Acmperen $s / s / 2015$

Dr. (Ms.) S. A. C. N. Perera

(External supervisor) 
Table of contents ................................................................................................

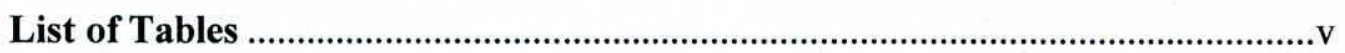

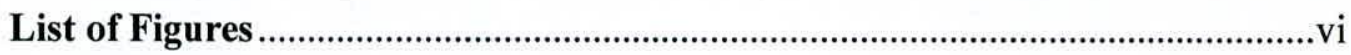

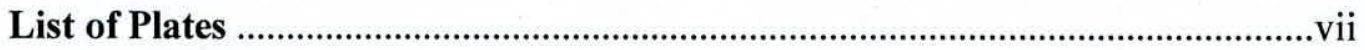

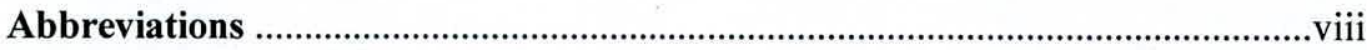

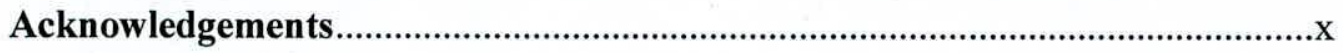

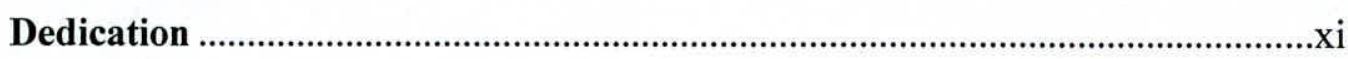

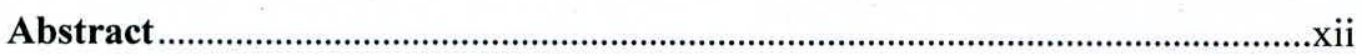

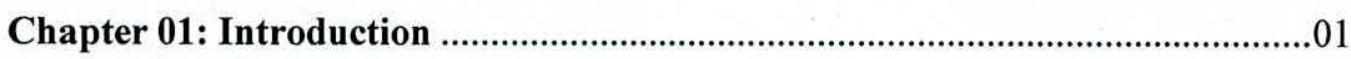

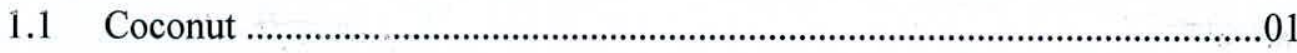

1.2 Coconut Genetic Resources in Sri Lanka...................................................

1.3 Conserved Coconut Germplasm.....................................................................

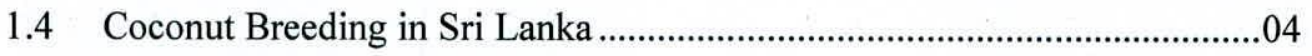

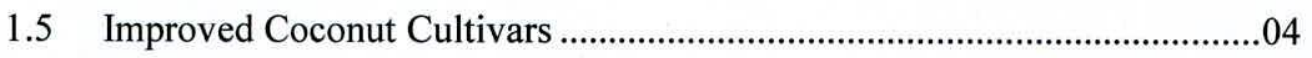

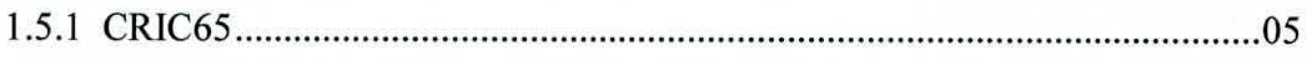

1.6 Sri Lankan Yellow Dwarf Populations ......................................................05

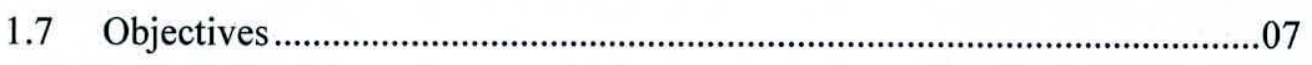

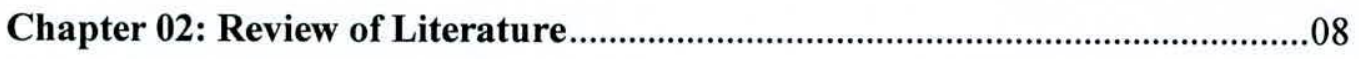

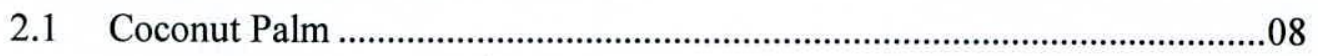

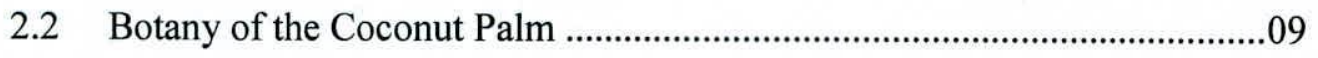

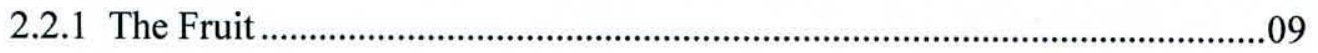




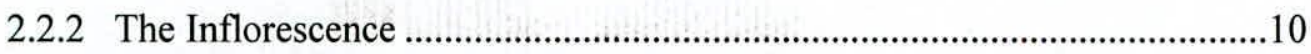

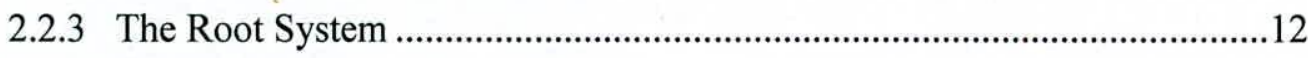

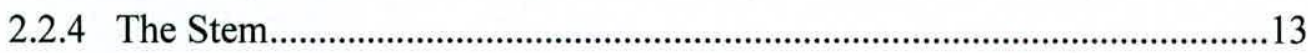

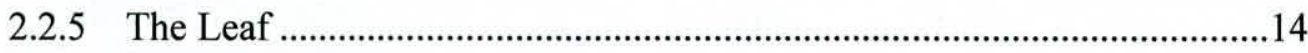

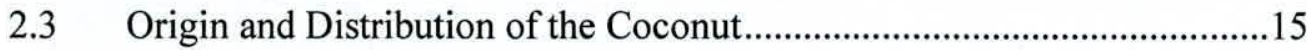

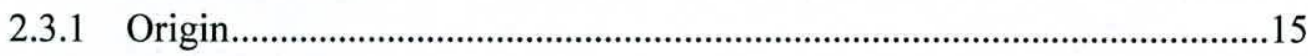

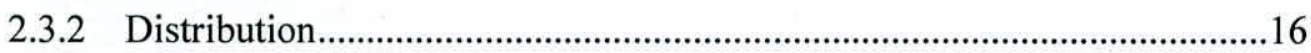

2.4 Taxonomic Classification of Coconut .......................................................17

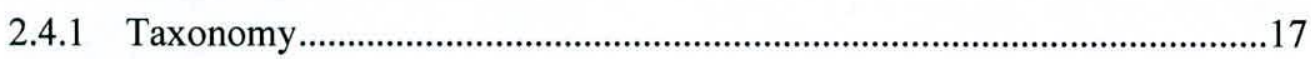

2.4.2 Classification of Coconut in Sri Lanka ................................................17

2.5 Coconut Breeding in Sri Lanka ...........................................................19

2.5.1 Objectives of Coconut Breeding …........................................................22

2.5.2 Improved Coconut Cultivars in Sri Lanka ..............................................22.

2.5.2.1 CRIC60

2.5.2.2 CRIC65

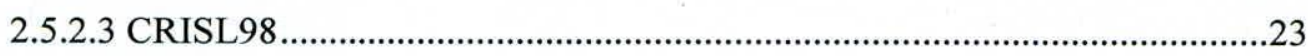

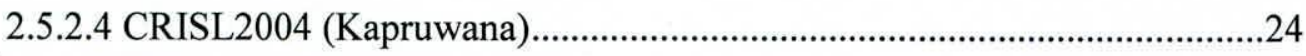

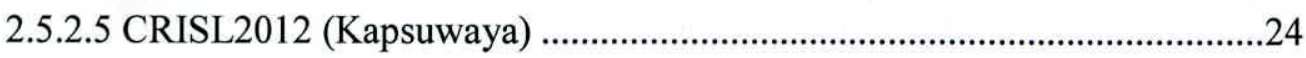

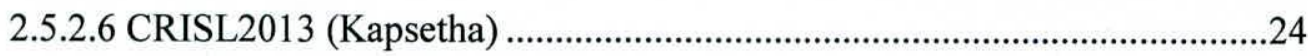

2.6 Mass Production and Isolated Coconut Seed Gardens ..............................24

2.7 Collecting and Conservation of Coconut Germplasm..............................26

2.8 Morphological Characterization and Evaluation.....................................27

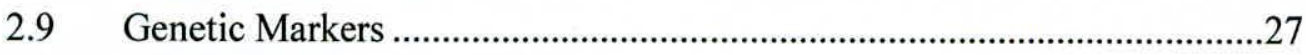

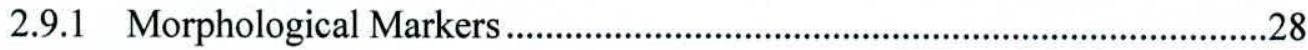


2.9.2 Molecular markers

2.9.2.1 Amplified Fragment Length Polymorphisms (AFLPs) ............................30

2.9.2.2 Random Amplified Polymorphic DNA (RAPDs) ......................................31

2.9.2.3 Restriction Fragment Length Polymorphism (RFLPs) ............................32

2.9.2.4 Single Nucleotide Polymorphisms (SNPs)...............................................33

2.9.2.5 Simple Sequence Repeats (SSRs) ............................................................34

2.13 Molecular Characterization of Coconut ....................................................36

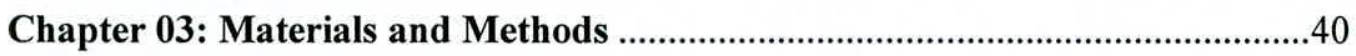

3.1 Site Selection and Sampling ...................................................................

3.2 Morphological Characterization .................................................................4

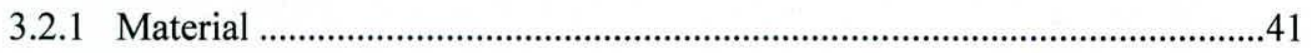

3.2.2 Descriptors for Morphological Characterization.........................................42

3.2.3 Detection of Pollination Behaviour .......................................................44

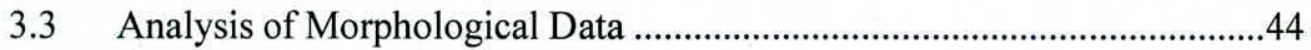

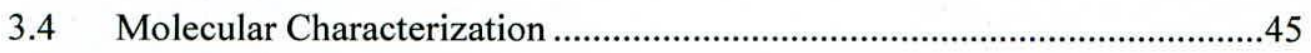

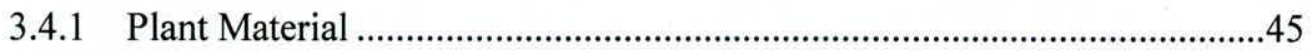

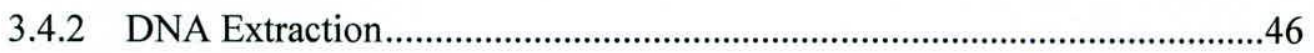

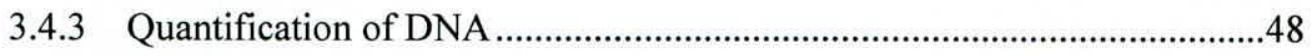

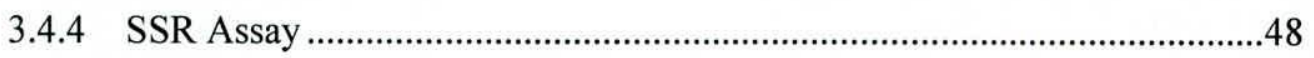

3.4.5 Polymerase Chain Reaction (PCR) ……...............................................51

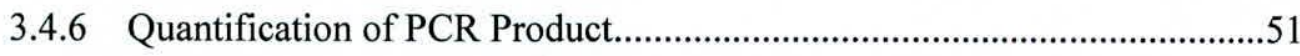

3.4.7 Denaturing Polyacrylamide Gel Electrophoresis (PAGE) ........................51

3.4.7.1 Preparation of Gel Electrophoresis Apparatus ..........................................51 


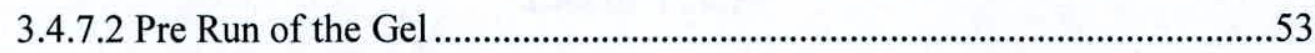

3.4.7.3 Sample Loading and Gel Electrophoresis ............................................53

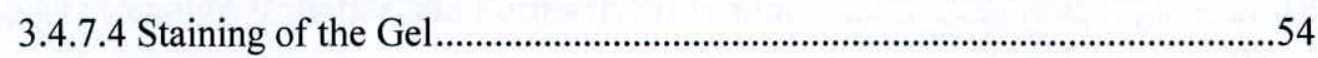

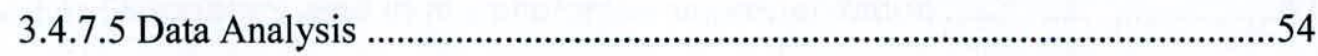

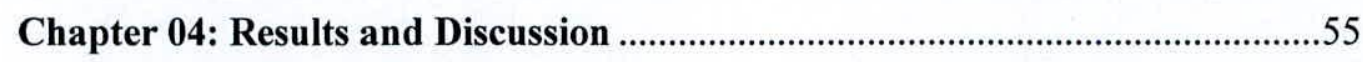

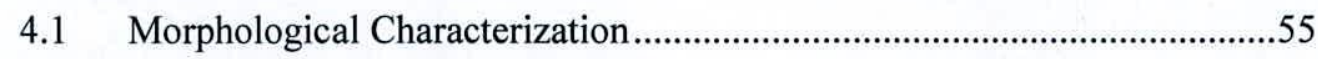

4.1.1 Descriptive Statistics and Analysis of Variance (ANOVA) .......................55

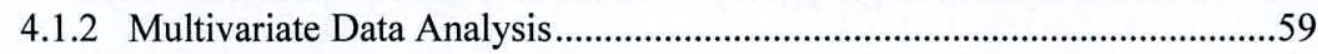

4.1.2.1 Principal Component Analysis (PCA) .......................................................59

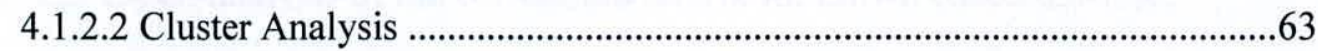

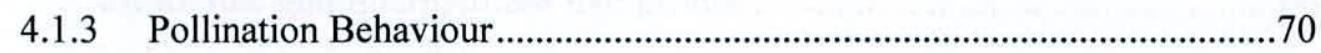

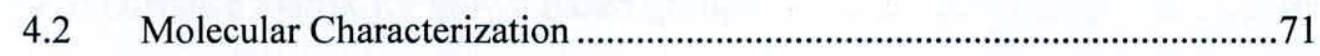

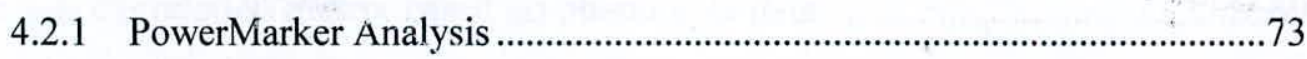

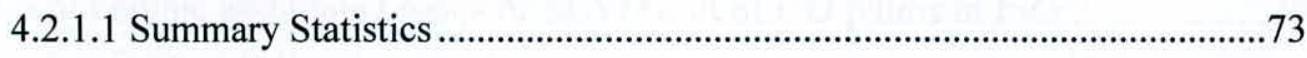

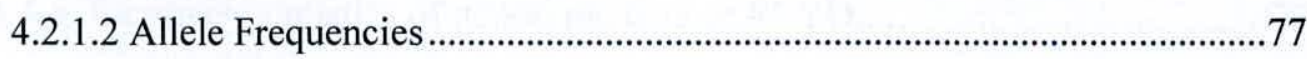

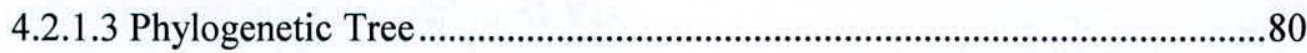

4.2.2 Population STRUCTURE analysis of SLYD coconut population .............82

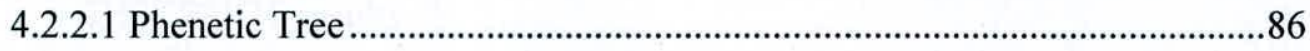

4.3 Combined Analysis of Morphology and Molecular Data .........................87

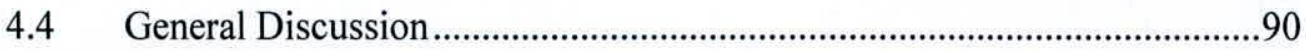

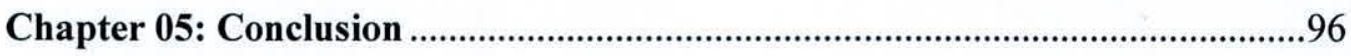

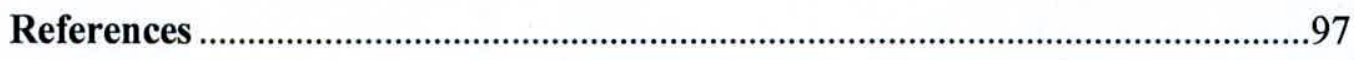

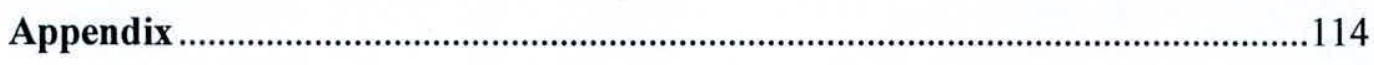




\section{List of Tables}

Table 2.1: Coconut Varieties and Forms in Sri Lanka............................................18

Table 3.1: Descriptors used in morphological characterization.................................42

Table 3.2: Palms used for the molecular characterization and their crown based

appearance

Table 3.3: Primer sequences, size of the PCR product and annealing temperatures of the microsatellite markers used for genotyping of coconut palms .49

Table 4.1 Descriptive statistics of crown based and bole based groups .56

Table 4.2: Eigen-analysis of the correlation matrix for crown based tall-like, dwarf-like and intermediate-like groups .60

Table 4.3: Distance matrix for crown based groups ..................................................62

Table 4.4: Correlation matrix based on phenotypic data .........................................69

Table 4.5: Female and male phases of SLYD and SLGD palms at ISG....................70

Table 4.6: Summary statistics of genotypic data of SLYD ........................................73

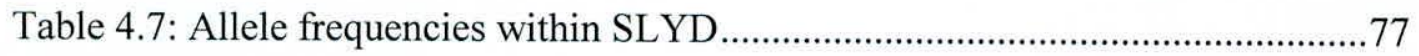

Table 4.8: Palm numbers corresponding to sample numbers given in STRUCTURE/ DISTRUCT results .85

Table 4.9: Comparison of Morphological and Molecular data .88 


\section{List of Figures}

Figure 4.1: PCA scatter plot for crown based groups ..............................................61

Figure 4.2: Dendrogram for crown based groups based on Euclidean distances......62

Figure 4.3: Dendrogram for inflorescences morphology based on Euclidean distances .64

Figure 4.4: Dendrogram for fruit component data based on Euclidean distances ....65

Figure 4.5: Dendrogram for yield characters based on Euclidean distances .66

Figure 4.6: Dendrogram for stem and leaf morphology based on Euclidean distances

Figure 4.7: Graphical representation of the genotypes of each individual .72

Figure 4.8: UPGMA dendrogam showing clustering pattern between SLYD, SLT, SLGD and GT individuals . .81

Figure 4.9: Estimated population structure of SLYD population .83

Figure 4.10: Neighbor joining tree phylogeny of SLYD based on 30 SSR markers. 86 


\section{Abbreviations}

\begin{tabular}{|c|c|}
\hline APS & Ammonium persulfate \\
\hline AFLPs & Amplified Fragment Length Polymorphisms \\
\hline ANOVA & Analysis of Variance \\
\hline $\mathrm{Bp}$ & Base pair \\
\hline CGRD & Coconut Genetic Resources Database \\
\hline COGENT & Coconut Genetic Resources Network \\
\hline CGIAR & Consultative Group on International Agricultural Research \\
\hline CRISL & Coconut Research Institute of Sri Lanka \\
\hline DNA & Deoxyribonucleic Acid \\
\hline DW & Dry Weight \\
\hline DL & dwarf-like \\
\hline EDTA & Ethylenediaminetetraacetic acid \\
\hline $\mathrm{EC}$ & Equatorial Circumference \\
\hline FNW & Fresh Nut Weight \\
\hline G20 & Girth at $20 \mathrm{~cm}$ Height \\
\hline G150 & Girth at $150 \mathrm{~cm}$ Height \\
\hline GT & Gon Thembili \\
\hline $\mathrm{HW}$ & Husk Weight \\
\hline HNW & Husked Nut Weight \\
\hline IL & intermediate-like \\
\hline IPGRI & International Plant Genetic Resources Institute \\
\hline ISSR & Inter Simple Sequence Repeat \\
\hline ISG & Isolated Coconut Seed Garden \\
\hline KW & Kernel Weight \\
\hline LL & Leaflet Length \\
\hline LW & Leaflet Width \\
\hline WW & Liquid Endosperm Weight \\
\hline$\mu \mathrm{l}$ & Micro Litre \\
\hline NFF & Number of Female Flowers \\
\hline Y02-NI & Number of Inflorescences \\
\hline
\end{tabular}




\begin{tabular}{|c|c|}
\hline NL & Number of Leaflets \\
\hline $\mathrm{NC}$ & Nut Count \\
\hline Y02-FF & Annual Female Flower Production \\
\hline PD & Peduncle Diameter \\
\hline PL & Peduncle Length \\
\hline PtL & Petiole Length \\
\hline PT & Petiole Thickness \\
\hline PW & Petiole Width \\
\hline PAGE & Polyacrylamide Gel Electrophoresis \\
\hline PC & Polar Circumference \\
\hline PCR & Polymerase Chain Reaction \\
\hline PIC & Polymorphic Information Content \\
\hline PCA & Principal Component Analysis \\
\hline RL & Rachis Length \\
\hline RAPDs & Random Amplified Polymorphic DNA \\
\hline RFLPs & Restriction Fragment Length Polymorphism \\
\hline Y02-SF & Settings Flowers \\
\hline SW & Shell Weight \\
\hline SSRs & Simple Sequence Repeats \\
\hline SNPs & Single Nucleotide Polymorphisms \\
\hline SNW & Split Husked Nut Weight \\
\hline SWFF & Spikeletes with Female Flowers \\
\hline SWWFF & Spikeletes without Female Flowers \\
\hline SG & Stalk Girth \\
\hline $\mathrm{SH}$ & Stem Height \\
\hline SLGD & Sri Lanka Green Dwarf \\
\hline SLT & Sri Lanka Tall \\
\hline SD & Stranded Deviation \\
\hline TL & tall-like \\
\hline
\end{tabular}




\section{Acknowledgements}

I would like to express my deepest gratitude to my supervisor Dr. (Ms) S.A.C.N. Perera, Principal Research Officer of the Genetics \& Plant Breeding Division of the Coconut Research Institute of Sri Lanka, for her invaluable guidance, immeasurable support and cooperation provided to make this project success. I am also greatly indebted to my supervisor, Dr (Mrs.) Nilanthie Dassanayaka, Senior Lecturer of the University of Sri Jayawardenepura for valuable guidance, immense support and important advices kindly provided throughout this project.

I would like to express my sincere gratitude to Mr. Nandika Perera, Senior Scientist, Parentage Analysis Division, Genetech Molecular Diagnostics, Colombo 08, for his encouragement, guidance and support throughout the project which helped me immensely to complete the project successfully.

I am grateful to Dr. J.M.D.T. Everard, the former Deputy Director (Research) of the Coconut Research Institute of Sri Lanka for his valuable guidance, immense support and important advices kindly provided throughout this project.

I gratefully acknowledge Dr. Lalith Perera, Head of the Genetics and Plant Breeding Division of CRI and Mr. Dhammika N. Gunesekera, Owner, Genetech Molecular Diagnostics, Colombo 08, for granting permission to carry out this study as my M. Phil research at the Coconut Research Institute and Genetech respectively.

I would like to express my sincere gratitude to Mrs. Sandya Fernando, Experimental Officer, Mr. Gamini Jayawardana, CRI and all the pollination workers at Ambakelle.

A special word of thanks goes to all the staff members at Parentage Analysis Division, Genetech, Colombo 08, for their valuable support throughout the project.

I would like to acknowledge the financial assistance of the National Research Council, Sri Lanka under grant number 11-042.

Finally, I express my heartfelt gratitude to my parents and brother for their immeasurable love and care bestowed to me throughout my life. 
This thesis is dedicated to my loving parents 
groups based on the presence or absence of an apparent root bole. Furthermore, the selected palms were divided into three groups based on the appearance of crown: talllike (TL) group, dwarf-like (DL) group and intermediate-like (IL) group. Analysis of variance and multivariate data analytical methods were performed in SAS and MINITAB software for the analysis of morphology data. Out of these palms, 51 palms were selected randomly for the molecular characterization and a total of 30 microsatellite primer pairs were used for genotyping. Genotypic data were analysed by PowerMarker and STRUCTURE software to determine the genetic diversity and the population structure of Yellow dwarf coconuts.

Individual palm data, when subjected to multivariate discrimination did not reveal clear groupings within the sample population resulting in many overlapping groups. However, when the data of different morphology based groups were analysed the results indicated a separate TL group within this population and it was distant from DL and IL groups. DL and TL groups clearly separated out with different morphological features defining them. However even with this analysis intermediate group could not be defined with clear morphological features.

In PowerMarker dendrogram two major clusters and three sub cluster in one major cluster, resulting four clusters were obseverd. In STRUCTURE analysis four sub populations $(K=4)$ were identified with the highest probability values concluding four groups within SLYD population.

The population structure of Yellow dwarf coconut form was clearly revealed by the molecular data. Considering both morphological and molecular analysis, the SLYD population was categorized into pure SLYD, Yellow semi tall (new coconut form) and a further mixed two groups.

The semi tall coconut form should be included in the coconut classification in Sri Lanka and should be conserved in ex-situ field gene banks of coconut to be utilized in the coconut breeding programmes. Pure SLYD should be used as the female parent in the improved and recommended coconut hybrid CRIC65 (Yellow) to extract the maximum hybrid vigour. This needs to be carefully considered in planting parent populations at the development and upgrading of coconut seed gardens for mass production of the hybrids including SLYD as a parent. 
groups based on the presence or absence of an apparent root bole. Furthermore, the selected palms were divided into three groups based on the appearance of crown: talllike (TL) group, dwarf-like (DL) group and intermediate-like (IL) group. Analysis of variance and multivariate data analytical methods were performed in SAS and MINITAB software for the analysis of morphology data. Out of these palms, 51 palms were selected randomly for the molecular characterization and a total of 30 microsatellite primer pairs were used for genotyping. Genotypic data were analysed by PowerMarker and STRUCTURE software to determine the genetic diversity and the population structure of Yellow dwarf coconuts.

Individual palm data, when subjected to multivariate discrimination did not reveal clear groupings within the sample population resulting in many overlapping groups. However, when the data of different morphology based groups were analysed the results indicated a separate TL group within this population and it was distant from DL and IL groups. DL and TL groups clearly separated out with different morphological features defining them. However even with this analysis intermediate group could not be defined with clear morphological features.

In PowerMarker dendrogram two major clusters and three sub cluster in one major cluster, resulting four clusters were obseverd. In STRUCTURE analysis four sub populations $(K=4)$ were identified with the highest probability values concluding four groups within SLYD population.

The population structure of Yellow dwarf coconut form was clearly revealed by the molecular data. Considering both morphological and molecular analysis, the SLYD population was categorized into pure SLYD, Yellow semi tall (new coconut form) and a further mixed two groups.

The semi tall coconut form should be included in the coconut classification in Sri Lanka and should be conserved in ex-situ field gene banks of coconut to be utilized in the coconut breeding programmes. Pure SLYD should be used as the female parent in the improved and recommended coconut hybrid CRIC65 (Yellow) to extract the maximum hybrid vigour. This needs to be carefully considered in planting parent populations at the development and upgrading of coconut seed gardens for mass production of the hybrids including SLYD as a parent. 